\title{
Could a revision of the current guidelines for cancer drug use improve the quality of cancer treatment?
}

This article was published in the following Dove Press journal:

Therapeutics and Clinical Risk Management

30 January 2014

Number of times this article has been viewed

\section{Theodor H Lippert' \\ Hans-Jörg Ruoff' \\ Manfred Volm²}

'Medical Faculty, University of Tübingen, Tübingen, Germany;

${ }^{2}$ Medical Faculty, University of

Heidelberg, Heidelberg, Germany
Correspondence: Theodor H Lippert Erlenweg 38, 72076 Tübingen, Germany Tel +49 707। 62 I99

$\mathrm{Fax}+49$ 707I 6I 234

Email theodor-lippert@web.de

\begin{abstract}
Clinical practice guidelines are indispensable for such a variable disease as malignant solid tumors, with the complex possibilities of drug treatment. The current guidelines may be criticized on several points, however. First, there is a lack of information on the outcome of treatment, such as the expected success and failure rates. Treating not only drug responders but also nonresponders, that is, patients with drug resistance, must result in failures. There is no mention of the possibility of excluding the drug nonresponders, identifiable by special laboratory tests and no consideration is given to the different side effects of the recommended drug regimens. Nor are there any instructions concerning tumor cases for which anticancer drug treatment is futile. In such cases, early palliative care may lead to significant improvements in both life quality and life expectancy. Not least, there is no transparency concerning the preparation of the guidelines: persons cannot be identified who could give a statement of conflicts of interest, and responsibility is assumed only by anonymous medical associations. A revision of the current guidelines could considerably improve cancer treatment.
\end{abstract}

Keywords: anticancer drugs, quality of guidelines, critical remarks

\section{Introduction}

In recent years, clinical practice guidelines have acquired increasing significance for the management of diseases. Many medical organizations are now engaged in working out guidelines to assist doctors in choosing the best available treatment for specific illnesses. The flood of medical publications appearing every month in all medical areas makes it impossible for practicing doctors to keep informed about new developments. The evaluation of new results itself is often difficult: many aspects have to be considered in order to arrive at reasonable conclusions. Furthermore, the quality of guidelines may differ considerably. The American Institute of Medicine elaborated directions in 1990 for standardizing and optimizing clinical practice guidelines. ${ }^{1}$ Other guidelines, like International Conference on Harmonisation ( $\mathrm{ICH}$ ) efficacy guidelines and The European Medicines Agency's (EMEA) guidelines, appeared later. These deal, however, with different topics, such as the safety and quality of medical products or general information on medicaments.

Clinical practice guidelines are not always followed by doctors. In the case of lifethreatening diseases, however, physicians tend to comply more strictly with guidelines, thinking themselves to be on the safe side since they are supported by officially approved proposals. Among such instructions for treatment are the guidelines for anticancer drug treatment. There appears to be no general criticism of these and the position seems clear, ie, that cancerous tissue that cannot be totally removed by surgery or radiation has to be treated by anticancer drugs. Although therapeutical measures are mandatory 
from an ethical point of view, the proposed medication using such drugs is less well defined.

\section{The difficulty of preparing clinical practice guidelines for anticancer drug treatment}

Competent guidelines are essential for drug treatment in advanced cases of cancer; however, the selection of the right drug from the great quantity of anticancer drugs now available is a difficult problem., ${ }^{2,3}$ Textbooks on the clinical pharmacology of anticancer drugs are of little help. Although they describe the mechanisms of action of the drugs in use, they provide no further information about their effectiveness in different types of cancer or for the individual patient. Treatment results available as published reports of randomized controlled trials (RCTs) generally only cause confusion with their large number of variable outcomes. Great efforts, including sophisticated statistical concepts, have been undertaken to arrive at assessments. ${ }^{4,5}$ Valuable statements are made more complicated, however, by polychemotherapy, when two or more drugs in different dosages are used in the trials. The possibilities of different drug regimens appear to be almost endless.

Thus, the responsibility for finding the best drug for a cancer patient in special circumstances has been passed to oncological specialists who work out guidelines and try to keep them updated. There are now many organizations, medical associations, and governmental bodies that provide such guidelines. The most prominent of these is the National Comprehensive Cancer Network (NCCN), a nonprofit organization based on an alliance of 23 cancer centers in the United States. The NCCN guidelines cover $97 \%$ of cancer types and are used in over 115 countries. ${ }^{6}$ The power of the specialist teams of such a big organization is tremendous, and it seems that they endeavor to produce the best possible guidance in cancer treatment; yet, the administration of drugs according to the specialist guidance still produces a great number of failures. The question therefore arises whether the general recommendations are optimal, or whether they need to be improved.

\section{Points of criticism on present anticancer drug guidelines}

Guidelines may be compared to publications of medical journals, with similar integrity and trust in comprehensive preparation. Although they do not undergo a process of control by reviewers, they must offer a degree of transparency for the users, both doctors and patients alike. This implies that the authors of guidelines must be identifiable by name and business affiliation and present existing conflicts of interests with drug firms. Strong connections with pharmaceutical firms producing anticancer drugs may give rise to doubt about the authors' independent decisions. The American Society of Clinical Oncology (ASCO) has repeatedly discussed the need for disclosure of authors' connections with industry, yet a recent publication stated that the problem is still not satisfactorily solved. ${ }^{7}$ In addition, the underlying data, eg, results of RCTs that have been used to prepare the recommendations, should be declared. Without such information, the specialists' work lacks transparency: guidelines are usually produced by medical associations that do not give any information about the persons who prepared them, nor about the clinical data used for their recommendations.

In any case, the question arises as to how definitive conclusions can be drawn when no clinical RCT data show outstanding drug effects; that is, when only minimally differing therapeutic results are attained among the varying polychemotherapeutic regimens. Unfortunately, the general recommendations are not further discussed, although more information would be useful in the management of patients. For instance, more instruction on the toxicity of drugs in addition to their efficacy would be desirable. The recommended drug regimens may have different side effects. It also has to be taken into consideration that toxic side effects in polychemotherapy increase with the number of cytostatics used in the drug combination. ${ }^{8}$ The knowledge of serious side effects is of great importance when a choice among different regimens is possible; however, there will always be the danger that side effects are under-evaluated or even neglected in trials.

The prognosis of treatment is another point that is of significance for both doctors and patients, but this is usually neglected in guidelines. It would be very helpful to learn more about response rates in the RCTs, in order to be able to assess the balance between success and failure. To cite percentage figures when comparing trials, without revealing the exact number of cases from which they are derived, does not give a clear picture; percentages can distort reality.

RCT results so far available were not arrived at through personalized treatment. The one-size-fits-all strategy of previous trials presumed that a hypothetical average patient could be cured, with the result that only the lowest common denominator type of cancer treatment was attained. It is now generally recognized that neoplastic diseases show great individual variability in clinical behavior and thus respond very differently to drug treatment. This variability was already understood in the middle of the last century, and attempts were made to diagnose the individual action of the anticancer drugs prior 
to treatment. ${ }^{9,10}$ Unfortunately, few efforts have been made from the 1960 s to the present. ${ }^{9,10}$ to detect nonresponders. The great amount of discoveries regarding the mechanisms of cancer drug resistance ${ }^{11-14}$ have so far had little influence on the clinical management of drug administration. RCTs underlying the setting-up of guidelines only derive from unselected cases, that is, a mixture of drug-responding and drug-nonresponding patients; in other words, patients' stratification and personalized treatment have not been given any consideration. Recommendations based on such trials cannot come close to reliably predicting success.

\section{Discussion}

The need for help in navigating the complicated cancer drug scene by selecting appropriate cancer medication from the plethora available gives the general guidelines a position of monopoly. Much trust appears to be placed in the recommendations, since they are usually issued by highly recognized medical associations. Yet it may be overlooked that the treatment advice is based on trials with drug-resistant patients. The general credo that only empiric results of RCTs can be used to establish guidelines leads to the consequence that the recommendations also have similar high failure rates. Nevertheless, the guidelines are very welcome to most doctors, since they can proceed with the clinical treatment in "cook-book fashion," with only some inevitable adjustments for body size, age, sex, and a few other factors being necessary. The pharmaceutical industry also has an advantage from empiric treatment. Undiagnosed nonresponders receiving unjustified treatment increase the profit of the firms, which are thus able to sell more of their drugs. Some drug companies, however, have recently endeavored to increase the effectiveness of their agents by developing companion tests to identify patients for personalized treatment. Such new agents with companion tests are crizotinib for non-small-cell lung cancer treatment ${ }^{15}$ and vemurafenib for metastatic melanoma treatment. ${ }^{16}$ Great expectations for personalized cancer therapy are now being placed by the US Food and Drug Administration in companion diagnostics; however, some doubt has been expressed by clinicians at large cancer centers in the US as to whether companion diagnostics are better than what they can already offer. ${ }^{17}$ Treatment guidance by such tests may infringe on a pathologist's ability to apply their professional experience in characterizing each individual tumor and may negatively affect their options based on their own laboratory-developed tests for personal care. ${ }^{17}$ Further studies must now show whether the aim to treat only drug responders can be accomplished with companion diagnostics.
Clinical practice guidelines should also, for the sake of correctness, report about methods to diagnose drug resistance. The well-known fact that biochemical individuality exists, ie, that every patient's tumor is unique and may respond at different points in its development to different agents, should be mentioned..$^{18}$ It seems unbelievable that mainstream research so far has not given more attention to the necessity of individual care in tumor drug treatment. Detection of intrinsic and acquired drug resistance is very important in treating cancer patients, ${ }^{19}$ but is generally neglected in clinical practice. Efforts are devoted mainly to the search for drug responders. The present strategy to discover drug response is based on the search for new cancer cell signals, ie, suitable biomarkers - a difficult, largely unsolved task, considering the high growth variability of different cancer types. Research in targeted cancer therapy has discovered numerous tumor growth factors (kinases) and their inhibitors, but, so far, only small, select groups of cancer types profit from this. ${ }^{20}$ Many of the new anticancer drugs urgently need clinical biomarkers to help select patients likely to respond, ${ }^{21}$ yet biomarkers are not well suited for indicating drug resistance.

For this purpose, special methods have been developed. Intrinsic drug resistance can be diagnosed in vitro before treatment starts by fresh tumor cell culture tests, and acquired drug resistance can be identified in vivo at early stages of treatment with positron emission tomography (PET). ${ }^{22}$ Both types of test are based on the examination of drug action on living human tumor cells that contain their full complex biological features. Consequently, the individual resistance of different anticancer drugs, including polychemotherapy regimens, can be diagnosed. Although these methods are still not available for clinical routine practice, experienced laboratories and nuclear medicine units are able to perform the tests. The exclusion of nonresponders could make treatment more effective, especially now that so many new anticancer drugs without reliable targets are available. Cancer drug therapy has not improved much in recent times, in cases of solid tumors, ${ }^{23}$ in spite of much progress having been made in the fields of cancer genomics, biomarkers, and targeted drugs.

Drug treatment should come to an end when tumors do not respond. Guidelines for anticancer drug treatment may also deal with cases which do not respond to the drugs. Thus a paradigm shift seems necessary, with the admission that cancer should not be treated with anticancer drugs in all circumstances. This is only possible, however, when empiric treatment with a trial-and-error strategy is abandoned. It should be an ethical obligation to make tests available to diagnose drug nonresponders in routine clinical practice. So far, little effort in this direction can be seen and no indications are to be 
found in the general guidelines that draw attention to ways of preventing futile and destructive treatment with inappropriate cancer drug medication. In cases of general drug resistance, early palliative care may lead to significant improvements in both quality of life and life expectancy of the patients. ${ }^{24}$

\section{Conclusion}

Cancer treatment guidelines can be improved by pointing out that drug nonresponders can be excluded by using special resistance tests. This would, in many cases, avoid useless and harmful treatment such as results from the current empirical trial-and-error procedure. Additionally, it would enhance the effect of the antineoplastic therapy. Further, the guidelines should deal with the conditions of incurable cases, eg, when patients become untreatable with conventional anticancer drugs and require only palliative medicine.

Instruction on the various pharmacological properties of the drugs, in particular their toxic side effects, is desirable. This is of great importance when, for instance, a choice is possible among regimens with little difference in their efficacy. It would also be helpful for patients to learn about the prognosis of treatment expected by the experts who prepare the guidelines.

The sale of anticancer drugs is a very profitable business. Unbiased proposals for their use should be guaranteed by experts having no connection with the drug-marketing industry. Transparency can be provided by a declaration of conflicts of interest by the guideline-preparing experts.

The continued development of anticancer drugs requires supplementation to the general guidelines. The quality of the guidelines will only be guaranteed, however, when certain critical points are addressed.

\section{Disclosure}

The authors report no conflicts of interest in this work.

\section{References}

1. Committee to Advise the Public Health Service on Clinical Practice Guidelines, Institute of Medicine. Clinical Practice Guidelines: Directions for a New Program. Field MJ, Lohr KN, editors. Washington, DC: National Academic Press; 1990.

2. Kufe DW, Bast RC, Hait WN, et al, editors. Cancer Medicine Part IV Principles of Therapeutic Modalities. London: BC Decker Inc Hamilton; 2006:503-897.

Therapeutics and Clinical Risk Management

\section{Publish your work in this journal}

Therapeutics and Clinical Risk Management is an international, peerreviewed journal of clinical therapeutics and risk management, focusing on concise rapid reporting of clinical studies in all therapeutic areas, outcomes, safety, and programs for the effective, safe, and sustained use of medicines. This journal is indexed on PubMed Central, CAS,
3. Bragalone DL. Drug Information Handbook for Oncology. A Complete Guide to Combination Chemotherapy Regimens. Hudson, $\mathrm{OH}$ : Lexicomp; 2012.

4. Berry DA. Clinical trials and outcomes assessment. Statistical innovations in cancer research. In: Kufe DW, Bast RC, Hait WN, et al, editors. Cancer Medicine. London: BC Decker Inc Hamilton; 2006: 411-425.

5. Talcott JA. Clinical trials and outcomes assessment. Cancer outcomes. In: Kufe DW, Bast RC, Hait WN, et al, editors. Cancer Medicine. London: BC Decker Inc Hamilton; 2006:426-433.

6. NCCN Clinical Practice Guidelines in Oncology [webpage on the Internet]. National Comprehensive Cancer Network (NCCN). Available from: http://www.NCCN.org. Accessed.

7. American Society of Clinical Oncology. American Society of Clinical Oncology policy for relationships with companies: background and rationale. J Clin Oncol. 2013;31:2037-2042.

8. Kufe DW, Bast RC, Hait WN, et al, editors. Cancer Medicine Part VI, Cancer Management. London: BC Decker Inc Hamilton; 2006:1037-2282.

9. Dawson M, Dryden WF. Tissue culture in the study of the effects of drugs. J Pharm Sci. 1967;56:545-561.

10. Tanneberger S. Gewebekultur und Krebschemotherapie [Tissue culture and cancer chemotherapy]. Arch Geschwulstforsch. 1968;31:387-400. German.

11. Dickson RB, Lippmann ME, editors. Drug and Hormonal Resistance in Breast Cancer. New York: Ellis Horwood; 1995.

12. Pinedo HM, Giaccone G, editors. Drug Resistance in the Treatment of Cancer. Cambridge: Cambridge University Press; 1998.

13. Andersson B, Murray D, editors. Clinically Relevant Resistance in Cancer Chemotherapy. Dordrecht: Kluwer Academic Publishers; 2002.

14. Teicher BA, editor. Cancer Drug Resistance. Totowa, NJ: Humana Press; 2006

15. Shaw AT, Solomon B, Kenudson MM. Crizotinib and testing for ALK. J Natl Compr Canc Netw. 2011;9:1335-1341.

16. Halait H, Demartin K, Shah S, et al. Analytical performance of real-time PCR-based assay for V600 mutations in the BRAF gene, used as the companion diagnostic test for the novel BRAF inhibitor vemurafenib in metastatic melanoma. Diagn Mol Pathol. 2012;21:1-8.

17. Schmidt C. Challenges ahead for companion diagnostics. J Natl Cancer Inst. 2012;104:14-15.

18. Williams RJ. Biochemical Individuality. New Canaan, CT: Keats Publishing; 1998.

19. Lippert TH, Ruoff HJ, Volm M. Intrinsic and acquired drug resistance in malignant tumors. The main reason for therapeutic failure. Arzneimittelforschung. 2008;58:261-264.

20. Knight ZA, Lin H, Shokat KM. Targeting the cancer kinome through polypharmacology. Nat Rev Cancer. 2010;10:130-137.

21. Sawyers CL. The cancer biomarker problem. Nature. 2008;452: $548-552$.

22. Lippert TH, Ruoff HJ, Volm M. Current status of methods to assess cancer drug resistance. Int J Med Sci. 2011;8:245-253.

23. Faguet GB. The War on Cancer: An Anatomy of Failure, a Blueprint for the Future. Dordrecht: Springer; 2008.

24. Temel JS, Greer JA, Muzikansky A, et al. Early palliative care for patients with metastatic non-small-cell lung cancer. $N$ Engl $J$ Med. 2010;363:733-742.

\section{Dovepress}

EMBase, Scopus and the Elsevier Bibliographic databases. The manuscript management system is completely online and includes a very quick and fair peer-review system, which is all easy to use. Visit $\mathrm{http}: / /$ www.dovepress.com/testimonials.php to read real quotes from published authors. 